\title{
Reduction of chloride emission by thickening of metallurgical wastewater
}

\author{
Krzysztof Słowik ${ }^{1, *}$, Marcin Stec ${ }^{1}$, Tomasz Iluk $^{1}$, Andrzej Czaplicki ${ }^{1}$, and Mateusz Kochel ${ }^{1}$ \\ ${ }^{1}$ Institute for Chemical Processing of Coal, ul. Zamkowa 1, 41-803 Zabrze, Poland
}

\begin{abstract}
Purification and thickening tests of metallurgical industrial wastewater from sintering dust dechlorination unit were carried out. Raw wastewater of $\mathrm{pH} 6.95$ consisted primarily of $\mathrm{Zn}^{2+}, \mathrm{Pb}^{2+}, \mathrm{Cd}^{2+}, \mathrm{Tl}^{+}, \mathrm{Cl}^{-}$, $\mathrm{SO}_{4}^{-2}$, at concentrations of approx. 3,$200 ; 60 ; 11,500 ; 100 ; 40,100$ and $5,300 \mathrm{mg} / \mathrm{dm}^{3}$ respectively. The heavy metals removal consisted in chemical precipitation and sedimentation, firstly by sodium hydroxide, and secondly by sodium sulphide solutions resulting in average removal to levels below $1 \mathrm{mg} / \mathrm{dm}^{3}$. Moreover, the experimental studies of evaporation process confirmed the possibility of chloride ions reducing, the distillate yield was approx. $80 \%$ of the initial effluent stream. The solid product obtained by two-stage evaporation was characterized by satisfactory purity. The results indicate maturity of the applied processes for wastewater treatment, allowing conditions close to zero-liquid-discharge to be achieved.
\end{abstract}

\section{Introduction}

Wastewater containing high concentrations of heavy metals, chloride and sulphate ions comes mainly from mining, the smelting industry, plating processes or pigments, as well as manufacture of alloys and batteries. The zinc and lead production using the Imperial Smelting Process is performed in Huta Cynku "Miasteczko Śląskie" S.A. The primary raw materials used for the production of zinc and lead ores are concentrates, while the secondary raw material is scrap from zinc alloys. Depending on the raw material used, production is carried out as a sulphide or oxide campaign. The main sources of wastewater are the wet gas treatment process and the slag granulation processes. Additional streams are rain water, cooling water and other process waters containing toxic heavy metals.

Regardless of the raw material used in the production process, all wastewater is treated in the central wastewater treatment plant to achieve an environmentally acceptable level of harmful substances, which are limited by environmental protection regulations $[1,2]$. Toxic and carcinogenic properties of heavy metals like, $\mathrm{Pb}, \mathrm{Hg}$ and $\mathrm{Cd}$ have been confirmed $[3,4]$ and when entering natural watercourses the heavy metals are quickly and irreversibly incorporated into the food chain. Therefore, in the case of insufficient purification, these wastewaters can be an important source of environmental pollution in the areas to which they are discharged. Removal of metals and sulphates from wastewater from the production of non-ferrous metals is successfully carried out by means of a combination of chemical

* Corresponding author: kslowik@ichpw.pl 
precipitation, sedimentation, filtration, flotation, ultrafiltration, activated carbon filtration or reverse osmosis techniques [1].

Heavy metal-free wastewater still contains anions, which must also be reduced to acceptable values. The evaporation process is one of promising techniques allowing its application for wastewater treatment. It can be effective in solution thickening as well as for removing salts and other undesirable materials from wastewater in order to produce valuable solids and reusable high-quality water. There are various types of evaporators available on the market, e.g.: falling film, forced circulation, plate or thermal and mechanical vapour recompression system [5, 6]. As EPCON reports [7], the energy consumption is $8-40 \mathrm{kWh}$ per tonne of evaporated water, and it is possible to treat volumes ranged from $100 \mathrm{~kg} / \mathrm{h}$ to $100,000 \mathrm{~kg} / \mathrm{h}$ for commercial applications with water recovery up to $99 \%$.

As shown above, for the evaporation process, it is required to provide a significant amount of heat to evaporate the solvent, and to concentrate the solution. Therefore, the evaporation processes are particularly suitable for plants having waste heat streams.

Differences in waste heat parameters and wastewater composition force companies to develop systems which are tailored to their processes.

The investment and operating costs of such solutions are high, but where waste heat can be used, it is possible to reduce the high costs. Such solutions become more and more common in "zero liquid discharge applications".

Waste management, energy considerations and costs are some of the key factors that affect the search for new technological solutions that enable zero-waste production. This publication presents the results of a collaborative project entitled "Effective generation of electric power from metallurgical waste gases with simultaneous reduction of chloride ion emissions into the environment." The aim of the research was to remove heavy metals, chloride and sulphate anions from raw wastewater, as well as to recover water with the level of impurities enabling its reuse in the production process, in a combined process, utilizing waste heat from electricity production.

\section{Materials and methods}

The investigated wastewater was a raw effluent produced in a dechlorination unit in the plant operation with oxides used as the raw material. The raw filtrate was pumped from the leachate tank into a $1 \mathrm{~m}^{3} \mathrm{IBC}$ container and subsequently transported to the test site.

The pilot plant was located on site of HCM S.A. in Miasteczko Śląskie, and consisted of a batch reactor with a volume of $1,300 \mathrm{dm}^{3}$ equipped with a mechanical stirrer and a $\mathrm{pH}$ measurement system. It allows for cleaning of $900 \mathrm{dm}^{3}$ of raw wastewater in one test cycle. It was additionally equipped with three pumps: one for pumping raw wastewater from the container into the reactor, the second one for decanting the solution from the sludge after sedimentation, and the third one for filtrate circulation in the reactor and pumping the sludge into filtration bags. Solutions of reagents (sodium sulphide and sodium hydroxide) were stored in stirred tanks, from which they were supplied to the reactor by means of dosing pumps. The thickening and crystallization process was carried out in two steps. For preliminary concentration, a heat pump forced circulation evaporator, model PC F 0.7 FF, with distillate capacity of $700 \mathrm{dm}^{3}$ per day was used. In the second stage, the heat pump scraped evaporator, model R $150 \mathrm{~V} 3 \mathrm{FF} 1 \mathrm{~V}$, with distillate capacity of $150 \mathrm{dm}^{3}$ per day was used. Both evaporators were delivered by Veolia Water Technologies Italia Spa. Additionally, the IBC containers were used for collecting and storing distillate water, concentrate and treated wastewater. The wastewater treatment plant is presented in figure 1. 

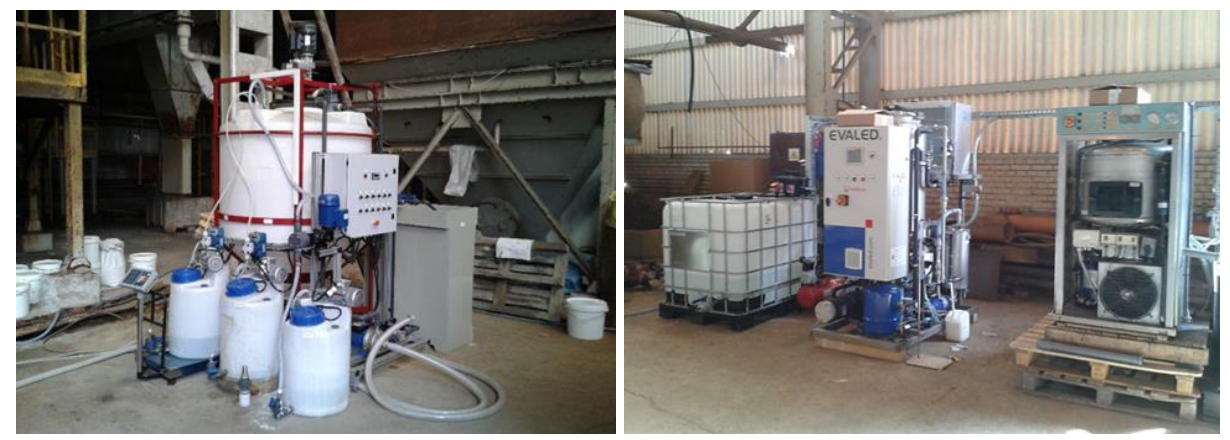

Fig. 1. Wastewater treatment pilot plant view (left - chemical neutralization unit, right - evaporation and crystallization unit).

The physicochemical properties like $\mathrm{pH}$, conductivity, temperature and redox potential of the samples obtained were determined directly during the experiments. The ELMETRON CPC-461 universal meter equipped with a glass combined $\mathrm{pH}$ electrode, a conductivity sensor with a platinum electrode and a type Pt-100 resistance temperature sensor was used.

The concentration of sulphide ions was determined by means of the EAg2S-305W type EUROSENSOR ion-selective electrode. As the reference electrode, the EAgClK-312 type electrode (EUROSENSOR) was used. The measurement of the potential difference between the electrodes was conducted using the ELMETRON CPC-461 meter.

A TCS Electronic Platform Scale was used to weigh chemical reagents and samples of distillate, concentrate and solid products. The sodium sulphide and hydroxide used in the treatment were of technical grade. The AXIS ATS 210 moisture analyser was used to determine the moisture content of materials as well as the salt content in concentrates at the temperature of $105^{\circ} \mathrm{C}$. Additionally, the device was used for density determination by measuring the weight of a given volume of concentrate. In order to determine the concentration of heavy metals, chloride and sulphate ions, sampled probes were sent to the plant's laboratory.

The contamination level of salt mixture was determined using the iCAP 6500 DUO Thermo Scientific Inductively Coupled Plasma Optical Emission Spectrometer and the Dionex ICS-5000 ion chromatograph.

Figure 2 presents a diagram of the procedure applied for purification and concentration testing.

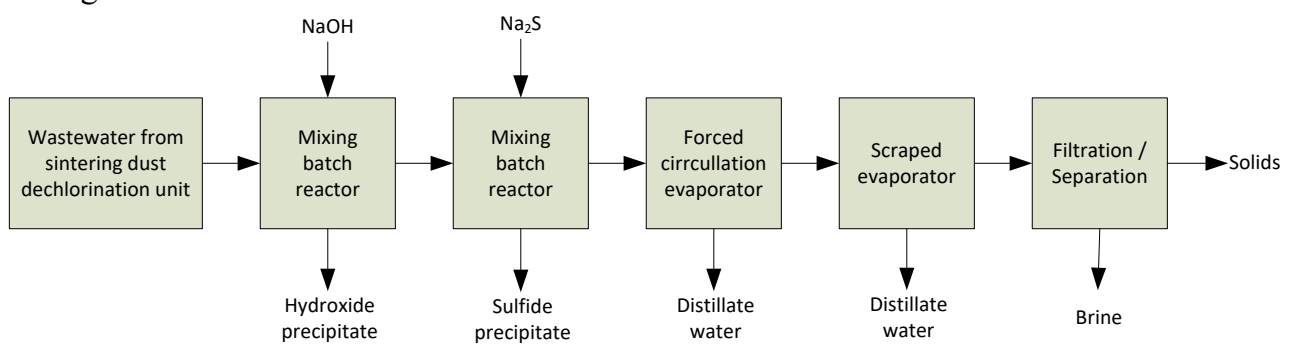

Fig. 2. Wastewater treatment process operations.

The chemical wastewater neutralization process was divided into two steps. In the first step, heavy metals $(\mathrm{Pb}, \mathrm{Zn}, \mathrm{Cd})$ were precipitated as hydroxides using $\mathrm{NaOH}$. The suspension thus obtained was allowed to sediment over the night (14 hours). The clarified solution was decanted to the intermediate container. The hydroxide mixture sludge was dewatered using fabric bag filters. The filtrate received from dewatering was subsequently 
added to the clarified solution. After the reactor cleaning, the pre-purified wastewater was pumped into the reactor for further treatment. In the second step of the heavy metals removal, a sodium sulphide solution was added to precipitate heavy metal sulphides (including thallium). Its dosing was controlled by measuring the potential difference of the cell with the ion-selective sulphide electrode $-\mathrm{pS}$. Once the sodium sulphide dosing had been completed, the suspension was left for sedimentation. The clarified solution was decanted to the container, and the remaining precipitate was separated with fabric bag filters. The filtrate received from dewatering was subsequently added to the clarified solution. In the second step, the sedimentation process was supported by adding a flocculant. The wastewater cleaned of heavy metals was directed to the tank of the concentration and crystallization system.

The evaporation process was performed in two steps. The first one consisted in initial concentration of the feed wastewater in the first evaporator (model PC F 0.7 FF3) without crystallization. Thus produced, the streams of concentrate and distillate water were collected in dedicated containers. Subsequently, the concentrate was automatically sampled into the second evaporator ( $\mathrm{R} 150 \mathrm{~V} 3 \mathrm{FF} 1 \mathrm{~V}$ ) and evaporation process was continued with production of the solid. The device was operated periodically, allowing salt mixture and brine removal after experiment was finished. The solid product was dewatered using paper bag filters. The products thus obtained were weighted, and the samples were sent to the laboratory for qualitative and quantitative analysis. The stability of operating parameters for both evaporators were periodically checked.

\section{Results and discussion}

The wastewater treatment was carried out from 13.09.2018 to 26.09.2018. The results of the wastewater treatment are shown in Table 1. In the first treatment step, where the $\mathrm{pH}$ value exceeded 10.5 , the process was stopped. It was found that chemical precipitation by $\mathrm{NaOH}$ including sedimentation and filtration significantly decreases the content of $\mathrm{Zn}, \mathrm{Pb}$ and $\mathrm{Cd}$, contrary to thallium. Thallium (I) hydroxide is well soluble [8], which is why it does not precipitate in the first treatment step. The remaining heavy metals, especially thallium, were precipitated by $1 \mathrm{M}$ sodium sulphide solution added in the second treatment step. The amount of the sodium sulphide added to the solution was controlled with the concentration of $\mathrm{S}^{2-}$ ions in accordance with a procedure proposed by Veeken et al. [9]. Its dosing was continued until the value of $-496,8 \mathrm{mV}$. High reactivity of sulphide ions $\left(\mathrm{S}^{-2}\right.$ and $\left.\mathrm{HS}^{-}\right)$with heavy metals and very low solubility of most heavy metal sulphides makes it possible to significantly improve the efficiency of wastewater treatment. This method requires precise control of sulphide ions concentration in the solution in order to prevent the possible odor of gaseous hydrogen sulphide. As for thallium and zinc after $\mathrm{Na}_{2} \mathrm{~S}$ addition, their concentration was satisfactorily reduced to the level fulfilling discharge standards.

Table 1. Results of treatment for $\mathrm{Zn}, \mathrm{Pb}, \mathrm{Cd}, \mathrm{Tl}, \mathrm{Cl}^{-}, \mathrm{SO}_{4}{ }^{2-}$ removal by 2 step chemical neutralization.

\begin{tabular}{|c|c|c|c|c|c|c|}
\hline \multirow{2}{*}{ Treatment step } & \multicolumn{7}{|c|}{ Contaminant concentration, mg/l } \\
\cline { 2 - 7 } & $\mathrm{Zn}^{2+}$ & $\mathrm{Pb}^{2+}$ & $\mathrm{Cd}^{2+}$ & $\mathrm{Tl}^{+}$ & $\mathrm{Cl}^{-}$ & $\mathrm{SO}_{4}{ }^{2-}$ \\
\hline Wastewater & 3214.4 & 58.47 & $11,423.25$ & 92.19 & 40,123 & 5,330 \\
\hline First neutralization & 7.29 & 0.82 & 34.13 & 80.1 & 43,827 & 4,850 \\
\hline $\begin{array}{c}\text { Second } \\
\text { neutralization }\end{array}$ & 0.74 & 0.91 & 1.59 & 0.73 & 42,592 & 4,371 \\
\hline
\end{tabular}


The wastewater discharge standard of the Polish Ministry of Environment for $\mathrm{Zn}, \mathrm{Pb}$, $\mathrm{Cd}$, and $\mathrm{Tl}$ is not more than $2 ; 0.5 ; 0.4 ; 1.0 \mathrm{mg} / \mathrm{l}$, respectively, and the chloride and sulphate concentration should not excess 1,000 and $500 \mathrm{mg} / \mathrm{l}$.

The received treatment results are in line with published data for processes utilizing similar treatment method namely: two-step heavy metals precipitation using caustic and sodium sulphide. Charemtanyarak [10] showed that precipitation using lime followed by $\mathrm{Na}_{2} \mathrm{~S}$ allowed reduction of zinc and cadmium to 1.0 and $1.5 \mathrm{mg} / \mathrm{dm}^{3}$, respectively. The synthesized raw wastewater, used in the cited experiments, contained initially $450 \mathrm{mg} / \mathrm{dm}^{3}$ of zinc and $150 \mathrm{mg} / \mathrm{dm}^{3}$ of cadmium and the initial concentration was smaller by the order of magnitude, comparing to wastewater presented in this paper. Despite significantly smaller concentration in the raw wastewater, the achieved results of the treatment are similar.

Treatment by precipitation of wastewater having a high initial concentration of the cadmium was presented by Islamoglu et al. [11]. In their research, the original sample contained $\sim 25000 \mathrm{mg} / \mathrm{dm}^{3}$ of cadmium, and its concentration was reduced to $\sim 8 \mathrm{mg} / \mathrm{dm}^{3}$ by precipitation using $\mathrm{Na}_{2} \mathrm{~S}$. The results are, again, in line with the data presented in this paper.

The acrylamide based flocculating agent solution was added for sedimentation of metal sulphides, which particularly favourably influenced the volume and grain size of the precipitated thallium sulphide.

The density values decreased slightly compared to raw wastewater, and they amounted to $1.068 \mathrm{~g} / \mathrm{cm}^{3}$ after the chemical neutralization steps. The conductivity value of the solutions did not change significantly, and it amounted to $175 \mathrm{mS} / \mathrm{cm}$ after the second treatment step. The $\mathrm{pH}$ value for the $\mathrm{NaOH}$ treated wastewater dropped from the initial value of 10.5 to 10.15 after its overnight conditioning, sedimentation and filtration. However, after the precipitation of the remaining heavy metals and thallium as sulphides in the second step, the $\mathrm{pH}$ value reached 10.32 . The average content of solids in the wastewaters subject to examination was $10 \%$ by weight. The determined values of physicochemical parameters for raw and chemically treated wastewaters are presented in Table 2.

Table 2. Values of physicochemical parameters of treated wastewater.

\begin{tabular}{|c|c|c|c|c|}
\hline \multirow{2}{*}{ Treatment step } & \multicolumn{4}{|c|}{ Parameter } \\
\cline { 2 - 5 } & $\mathrm{pH}$ & Conductivity, $\mathrm{mS} / \mathrm{cm}$ & Solids, \% & Density, g/cm ${ }^{3}$ \\
\hline Wastewater & 6.19 & 164.36 & 9.1 & 1.074 \\
\hline First neutralization & 10.15 & 163.26 & 10.9 & 1.069 \\
\hline Second neutralization & 10.32 & 175.04 & 10.1 & 1.068 \\
\hline
\end{tabular}

After chemical neutralization, anions with very high concentrations were still present in the treated wastewater. The initial wastewater concentration test in the first evaporator was conducted with the cycle time of $350 \mathrm{~s}$ (frequency of concentrate discharging from the evaporator). The operating parameters as well as $\mathrm{Q}^{\mathrm{I}}-$ distillate stream, $\mathrm{m}_{\mathrm{c}}{ }^{\mathrm{I}}-$ mass of concentrate (one discharge) and concentrate density $-\mathrm{d}_{\mathrm{c}}{ }^{\mathrm{I}}$ were periodically controlled. The values are presented in Table 3 and confirm the process stability.

The determined average yield of the distillate was $27.58 \mathrm{~kg} / \mathrm{h}(662 \mathrm{~kg}$ per day) at the average boiler pressure (vacuum ) of $5.3 \mathrm{kPa}$, which confirms the declared nominal parameters for the evaporator used for the initial concentration of the treated wastewater. The produced distillate water was characterized by an average conductivity of $131 \mu \mathrm{S} / \mathrm{cm}$. The average mass of concentrate per one discharge equalled $2.09 \mathrm{~kg}$, which corresponded to $21.5 \mathrm{~kg}$ of concentrate per hour. 
Table 3. Operating parameters in the first evaporation step.

\begin{tabular}{|c|c|c|c|c|c|}
\hline \multicolumn{7}{|c|}{ PC F 0.7 FF3 operating parameters } \\
\hline $\begin{array}{c}\text { Duration time, } \\
\text { min. }\end{array}$ & $\mathrm{Q}^{\mathrm{I}}, \mathrm{kg} / \mathrm{h}$ & $\mathrm{m}_{\mathrm{c}}{ }^{\mathrm{I}}, \mathrm{kg}$ & $\mathrm{d}_{\mathrm{c}}{ }^{\mathrm{I}}, \mathrm{g} / \mathrm{cm}^{3}$ & $\begin{array}{c}\text { Boiler } \\
\text { pressure, } \mathrm{kPa}\end{array}$ & $\begin{array}{c}\text { Distillate } \\
\text { conductivity, } \\
\mu \mathrm{S} / \mathrm{cm}\end{array}$ \\
\hline 37 & 27.96 & 2.12 & 1.139 & 5.3 & 140 \\
\hline 170 & 27.48 & 1.94 & 1.131 & 5.2 & 129 \\
\hline 240 & 27.48 & 2.28 & 1.126 & 5.3 & 130 \\
\hline 300 & 27.48 & 2.16 & 1.123 & 5.4 & 126 \\
\hline 356 & 27.48 & 1.96 & 1.124 & 5.3 & 128 \\
\hline Average & 27.58 & 2.09 & 1.129 & 5.3 & 131 \\
\hline
\end{tabular}

The second evaporator was operated for 7.25 hours, the boiler pressure (vacuum) and the distillate stream $\left(\mathrm{Q}^{\mathrm{II}}\right)$ were controlled periodically and are presented in Table 4 .

Table 4. Operating parameters in the second evaporation step.

\begin{tabular}{|c|c|c|}
\hline \multicolumn{3}{|c|}{ R 150V3 FF1 V operating parameters } \\
\hline Duration time, $\min$. & $\mathrm{Q}^{\mathrm{II}}, \mathrm{kg} / \mathrm{h}$ & Boiler pressure, $\mathrm{kPa}$ \\
\hline 75 & 6.00 & 4.5 \\
\hline 200 & 5.76 & 4.5 \\
\hline 260 & 5.60 & 4.0 \\
\hline 369 & 5.36 & 4.0 \\
\hline 419 & 5.52 & n.a. \\
\hline Average & 5.51 & 4.3 \\
\hline
\end{tabular}

n.a. - data not available

The determined average yield of the distillate was $5.51 \mathrm{~kg} / \mathrm{h}(132.2 \mathrm{~kg}$ per day) at the average boiler pressure of $4.3 \mathrm{kPa}$. The values confirm the nominal parameters for the evaporator used for salt crystallization. The determined values of conductivity, content of solids and density of the concentrates obtained are provided in Table 5.

Table 5. Physicochemical parameters of concentrates.

\begin{tabular}{|c|c|c|c|}
\hline \multirow{2}{*}{ Treatment step } & \multicolumn{3}{|c|}{ Parameter } \\
\cline { 2 - 4 } & Conductivity, $\mathrm{mS} / \mathrm{cm}$ & Solids, \% & Density, $\mathrm{g} / \mathrm{cm}^{3}$ \\
\hline First evaporation & 379.4 & 20.9 & 1.129 \\
\hline Second evaporation & 472.0 & 29.7 & 1.262 \\
\hline
\end{tabular}

The thickening of the solutions is indicated by the density increase from 1.068 to $1.129 \mathrm{~g} / \mathrm{cm}^{3}$ after the first step, subsequently reaching the value of $1.262 \mathrm{~g} / \mathrm{cm}^{3}$ for brine after the second evaporation. The content of solids in the solutions increased from $10.1 \%$ for chemically treated wastewater, to $20.9 \%$ after the first evaporation, and to $29.7 \%$ by weight for the brine thus produced. Also, the conductivity of the concentrated solutions increased from 175 to 379 after the first evaporation step, finally reaching $472 \mathrm{mS} / \mathrm{cm}$ for the brine.

The $22.26 \mathrm{~kg}$ of brine were produced during the crystallization test. The determined concentration of chlorides changed from the initial 42,592 to 98,710 after the first evaporation, and subsequently up to $200,645 \mathrm{mg} / \mathrm{l}$ in brine.

Results presented by M. Turek et al. [12] shows "Debiensko" Desalination Plant performance on concentration of coal-mine brine with a TDS of about $60 \mathrm{~g} / \mathrm{dm}^{3}$ in two stage evaporation process. From initial $32.8 \mathrm{~g} / \mathrm{dm}^{3}$ of $\mathrm{Cl}^{-}$content in coal-brine the concentration increased to $175.9 \mathrm{~g} / \mathrm{dm}^{3}$ after first evaporator (falling film with vapour compression). After crystallization step the concentration of chlorides reached $205.6 \mathrm{~g} / \mathrm{dm}^{3}$ what is in well correspondence with our result. 
The $5.32 \mathrm{~kg}$ of wet salt mixture was obtained with the moisture content of $\sim 19 \%$. The total concentration of anions and cations determined in the dried salts sample equalled $931 \mathrm{~g} / \mathrm{kg}$, and consisted primarily of: $\mathrm{Cl}^{-}-519.9, \mathrm{SO}_{4}^{-2}-29.3, \mathrm{~K}^{+}-20.8, \mathrm{Na}^{+}-360.5 \mathrm{~g} / \mathrm{kg}$. The concentration of other cations, i.e. $\mathrm{Cd}^{2+}, \mathrm{Pb}^{2+}, \mathrm{Zn}^{2+}, \mathrm{Tl}^{+}, \mathrm{Ca}^{2+} \mathrm{Mg}^{2+}$, was $10.3,6.0,1.0$, $3.0,92.5$ and $58.8 \mathrm{mg} / \mathrm{kg}$, respectively. Based on the values determined, the content of chloride ions accounted for $56 \%$, which confirms the possibility of effective reduction of the environmental emissions of these ions. Based on the measured values, it was estimated that the yield of the distillate was $\sim 81 \%$ of the initial wastewater stream.

\section{Conclusions}

Despite the very high content of heavy metal cations as well as chloride and sulphate anions in the treated wastewater, the proposed procedure allowed for a properly purified filtrate to be produced. The results indicated that the treatment technology for removal of heavy metals should use a combination of hydroxide and sulphide precipitation, particularly necessary for thallium removal. The effectiveness of using a vacuum evaporator system to recover fresh water as well as to remove chloride and sulphate ions from the tested wastewater was confirmed. No significant technical problems were encountered during the experimental work. The major benefits of the technology implementation are as follows:

- high quality water recovery,

- reduction of chloride and sulphide ions emission,

- $\quad$ overall zinc yield of the plant (recycle of precipitated hydroxide to the process).

It is also economically sound to apply the proposed technology under the technical and technological conditions of Huta Cynku Miasteczko Śląskie S.A. It is expected to trigger the following two effects:

- $\quad$ energy-saving effect, by utilising waste heat,

- environmental effect, by reducing the concentration and load of harmful substances discharged into the environment.

This research was conducted under agreement no. 1/BR/2016 concluded between HCM S.A. and the Institute for Chemical Processing of Coal for the performance of a project entitled "Effective generation of electric power from metallurgical waste gases with simultaneous reduction of chloride ion emissions into the environment" co-financed by the Polish National Centre for Research and Development under Sectoral Programme INNOSTAL no. POIR.01.02.00-00-0170/1, the 2014-2020 Smart Growth Operational Programme.

\section{References}

1. G. Cusano, M. R. Gonzalo, F. Farrell, R. Remus, S. Roudier, L. Delgado Sancho, Best Available Techniques (BAT) Reference Document for the Non-Ferrous Metals Industries, Industrial Emissions Directive 2010/75/EU Integrated Pollution Prevention and control, (2017)

2. Regulation of the Minister of the Environment of November 18, 2014 on the conditions to be met when introducing sewage into waters or into the ground, and on substances particularly harmful to the aquatic environment (in Polish).

3. J. Godt, F. Scheidig, C. Grosse-Siestrup, V. Esche, P. Brandenburg, A. Reich, D. A. Groneberg, J. Occup. Med Toxicol. 1, 22 (2006)

4. P. B. Tchounwou, C. G. Yedjou, A. K. Patlolla, D. J. Sutton, Experientia Supplementum 101, 133-164 (2012) 
5. GEA engineering for a better world, available on:

http://www.gea.com/en/applications/chemicals/treatment_of_emissions/treatment_emis sions_evaporation.jsp.

6. EVALED ${ }^{\circledR}$ Evaporators - Evaporation technologies Veolia Group, available on: http://www.evaled.com/.

7. EPCON Evaporation Technology AS, available on: http://www.epcon.org/industrialwastewater.html

8. R. H. Perry, D. W. Green, J. O. Maloney, Perry's Chemical Engineers' Handbook (1997)

9. H. Veeken, L. Akoto, L. W. H. Pol, J. Weijma, Water Res. 37, 15, 3709-3717 (2003)

10. L. Charerntanyarak, Water Sci. Technol. 39, 10-11, 135-138 (1999)

11. S. Islamoglu, L. Yilmaz, H. O. Ozbelge, Sep. Sci. Technol. 41, 15, 3367-3385 (2006)

12. M. Turek, P. Dydo, R. Klimek, Desalination 184, 439-446 (2005) 